Críticas de exposiciones 



\title{
The State of Anonymous (VII Traducción). Stories from homes 3. Carlos Miranda
}

\author{
Galería JM. Málaga
}

\section{En los escenarios donde (sobre)vive la creación}

¿Tiene algo que ver la creación, sus procesos, objetivos y vicisitudes, con los espacios en los cuales se pergeña, se gesta, toma forma, se destruye y reconstruye lo creado? ¿Es posible establecer una casuística cualitativa y conceptual entre ambos extremos? Carlos Miranda construye espacios donde ofrecer respuestas a estos interrogantes en torno a la creatividad desde el otro y como otro. Y lo hace acortando al máximo la distancia que separa la representación (en cuanto que fijación de la imagen en el espacio y en el tiempo) del relato (en tanto que narración que se despliega por el espacio y por el tiempo), en un intento por buscar puntos de fricción y coincidencia entre campos artísticos (verbales o visuales) tangentes. Al fin y al cabo, el proyecto marco, titulado The
State of Anonymous, se despliega en capítulos como si de un manual literario sobre las claves que alumbran los procesos creativos se tratase [1].

Carlos Miranda (Málaga, 1971) continúa con una tercera entrega -tras las exhibidas en el Centro d'Arte Piana dei Colli de Palermo (2012) y en el espacio El Butrón de Sevilla (2013) - de una suerte de tour periegético por los espacios de trabajo del arte, que pronto se transforma en proceso reconstructivo que pretende, al mismo tiempo, ofrecernos el retrato diferido de un conjunto de autores de distintos campos de la cultura y, por otro, indagar sobre las especificidades de esos ámbitos secretos de producción en los cuales se alumbra la acción creadora.

Mediante un recurso bien estudiado a lo largo de su trayectoria, la heteronomía, el estatuto del autor único se

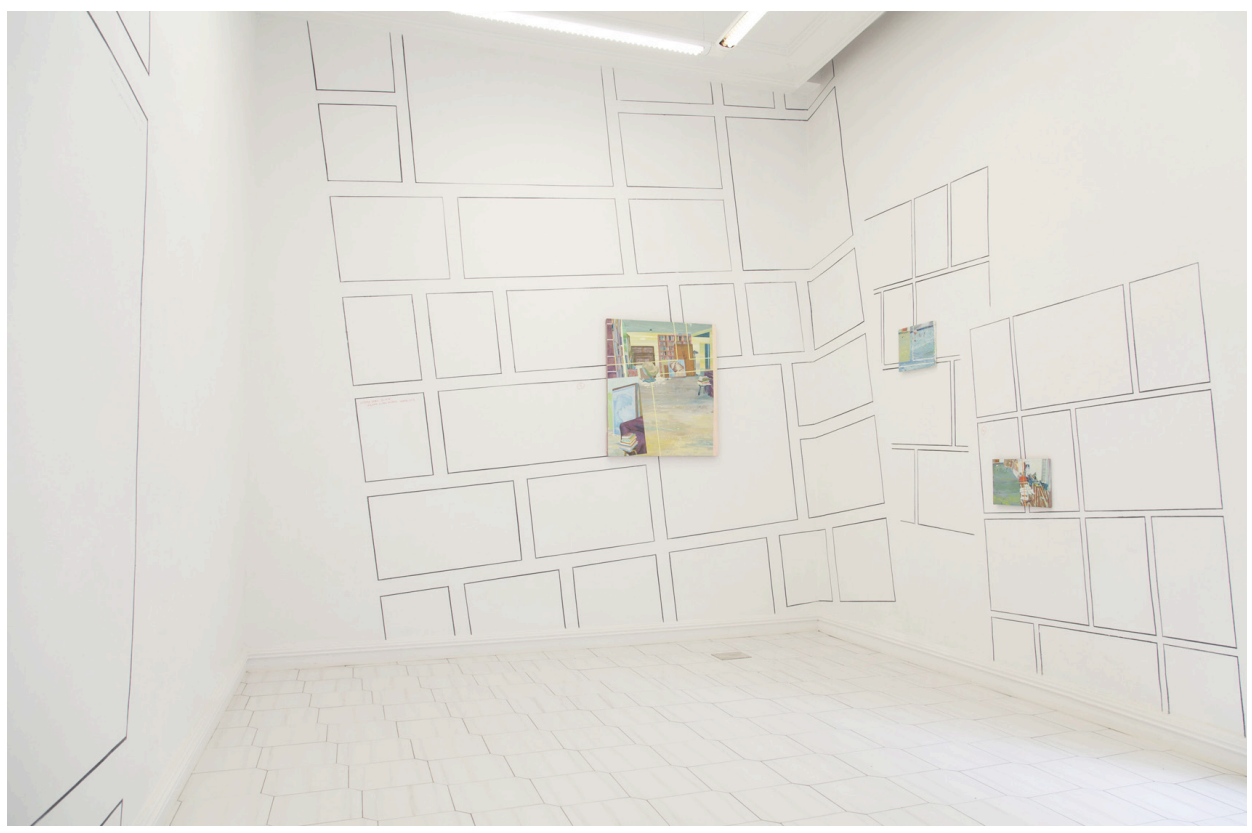

1. Vista de la exposición. Galería JM, Málaga, 2014. Carlos Miranda, Chema Cobo, «Blow». Galería Álvaro Alcázar, Madrid, 2012 


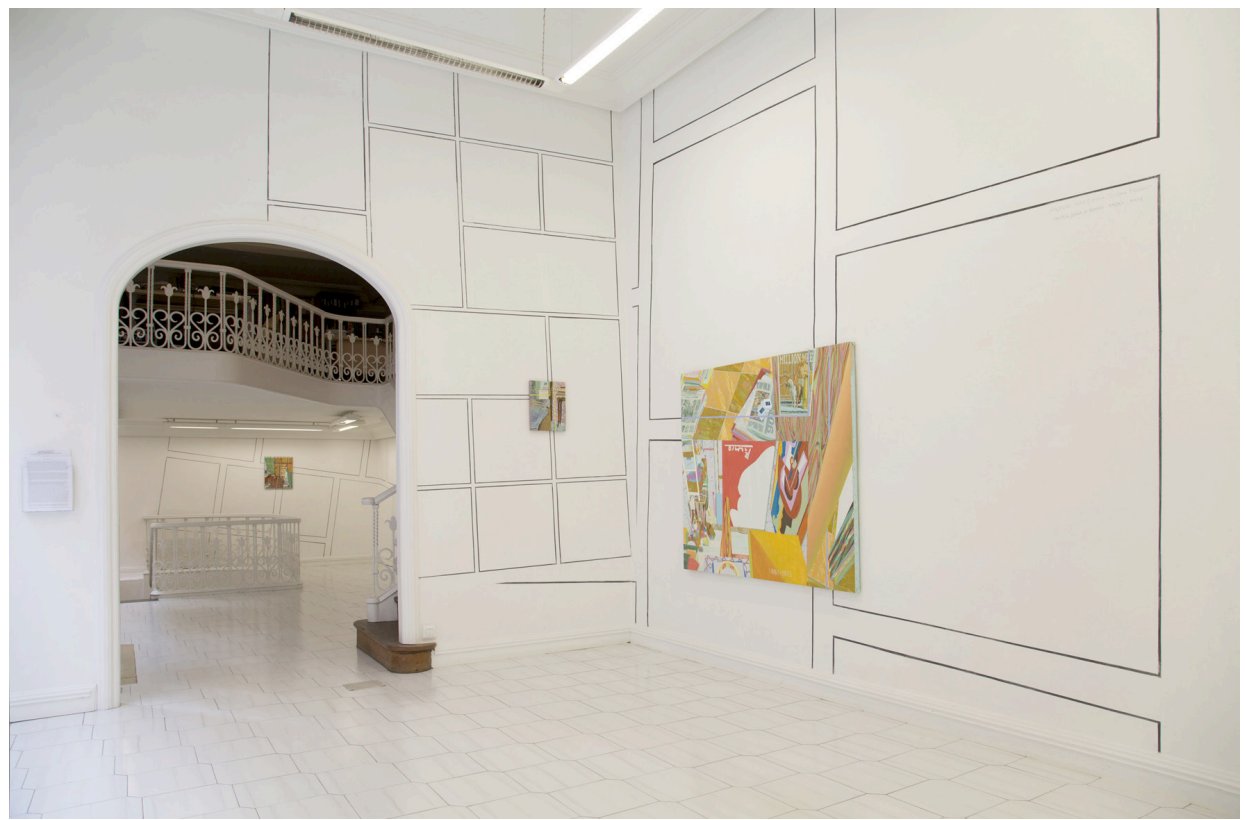

2. Vista de la exposición. Galería JM, Málaga, 2014. Carlos Miranda, Rogelio López Cuenca, «Ciudad Picasso». Galería Juana de Aizpuru, Madrid, 2011

pone en cuestión, se disemina y expande en tres coautores. A partir de la idea de Anonymous, instigador intelectual y enjuto viajero, y mediante la documentación gráfica aportada por la crítica de arte Polaroid Star, Carlos Miranda reconstruye los escenarios de trabajo de creadores de diversas facetas de la cultura, espacios íntimos donde acontece la creación. Un novelista (José Antonio Garriga Vela) que pergeña los últimos compases de su obra El cuarto de las estrellas, un sociólogo (Simone Lucido) que elucubra sobre las relaciones actuales entre crisis y urbanidad, artistas plásticos que trabajan en distintas piezas para futuros compromisos expositivos (Chema Cobo, Rogelio López Cuenca, Juan del Junco, Erika Pardo), un musicólogo y crítico literario (Carlo Lauro) que establece interconexiones entre Paul Léautaud y la ciudad de París, una gestora cultural, comisaria y experta en arte contemporáneo (Giulia Ingarao) que reflexiona sobre Leonora Carrington y los años en los que se afincó en México, son sorprendidos trabajando por una invitada indiscreta, la inefable Star. Y, sin embargo, ninguno de ellos aparece físicamente; todos quedan elididos y permanecen presentes exclusivamente a través del trabajo en proceso y del espacio donde este se desarrolla.
La mirada a estos territorios, cotidianos y privados, extraños y caóticos, más allá del puro desvelamiento de una sólida y monolítica realidad, se concibe en base a imágenes desdobladas, donde el fragmento ampliado -un cuadro dentro de un cuadro-, focaliza la representación y la condiciona, imponiéndose el detalle sobre el relato mayor del cual se desgaja, componiendo una realidad, si queremos nominarla así, alterada. La elección de la pintura como proceso y en tanto que medio, permite a Miranda alcanzar un doble objetivo. Por un lado, un artefacto de plasmación tan poco ágil y dinámico, permite cargar el peso de los procedimientos conceptuales en el trabajo mental de planificación y en los procesos de reflexión intelectual, sin dejar de lado un indisimulado apego por parte del artista hacia mecanismos artísticos casi artesanales, manuales, donde el arrepentimiento está proscrito o, en su defecto, donde toda acción siempre deja un rastro que no puede ser eliminado. Por otro lado, Miranda, a través de la pintura, lanza una mirada crítica sobre los géneros tradicionales, estableciendo concomitancias entre interiores, retratos y bodegones, en una suerte de hibridación práctico-conceptual que trasciende marcos muchas veces impuestos por 
los historiadores o, lo que es peor, por el sistema mercantil de las artes.

En The State of Anonymous (VII Traducción). Stories from Homes 3, Miranda interviene en la galería JM de la capital malagueña a lo largo y ancho del espacio, puesto que las obras pictóricas se articulan, se sobreponen, a una infraestructura que trama la superficie expositiva y transforma el neutro cubo blanco en una pauta gráfica que recuerda las viñetas, unidad mínima del cómic o la historieta [2]. Si la obra, para el artista -y de algún modo la instalación museográfica también lo es-, se nos revela por su carácter de indicio, la propuesta en su conjunto se presenta como una narración fragmentaria, de la cual apenas hemos podido rescatar breves vestigios. Esa voluntad por trazar marcos trasciende al interior del espacio pictórico -retículas que coinciden con las calles antes mencionadas- creando un doble desequilibrio: en su conjunto las imágenes no coinciden plenamente con ninguna viñeta, sino que pisan y militan en varias a un tiempo; en el interior de la representación el «tiralineado» propicia la superposición de imágenes generadas por miradas yuxtapuestas, muy en consonancia con prácticas cinematográficas, en distinto tiempo o distinta ubicación, de una misma realidad de por sí heterodoxa y mutable.

En muchos casos las obras de Miranda evidencian la indistinción en el ámbito creativo entre los espacios de lo doméstico y los lugares de trabajo. Esa convicción alcanza al propio artista, quien se atreve -lanzándose a un vacío insondable- a auscultar su realidad creativa y su ámbito de trabajo, asomándose a ella por el breve intersticio que le ofrece un lienzo de pequeñas dimensiones [3].

En arte, la obra nos revela la dimensión del espacio cotidiano, el espacio cotidiano del «otro», pero en este «desvelar» lo que acabamos apreciando es nuestro propio espacio cotidiano, limitado por la cercanía, que nos impide valorarlo en su justa medida mientras que, de algún modo, nos ayuda a poner en escena al artista -y también al espectador- en el teatro de la representación. Sin que el público los conozca, estas obras de Carlos Miranda suponen un vivo retrato de los habitantes de esos espacios. En este

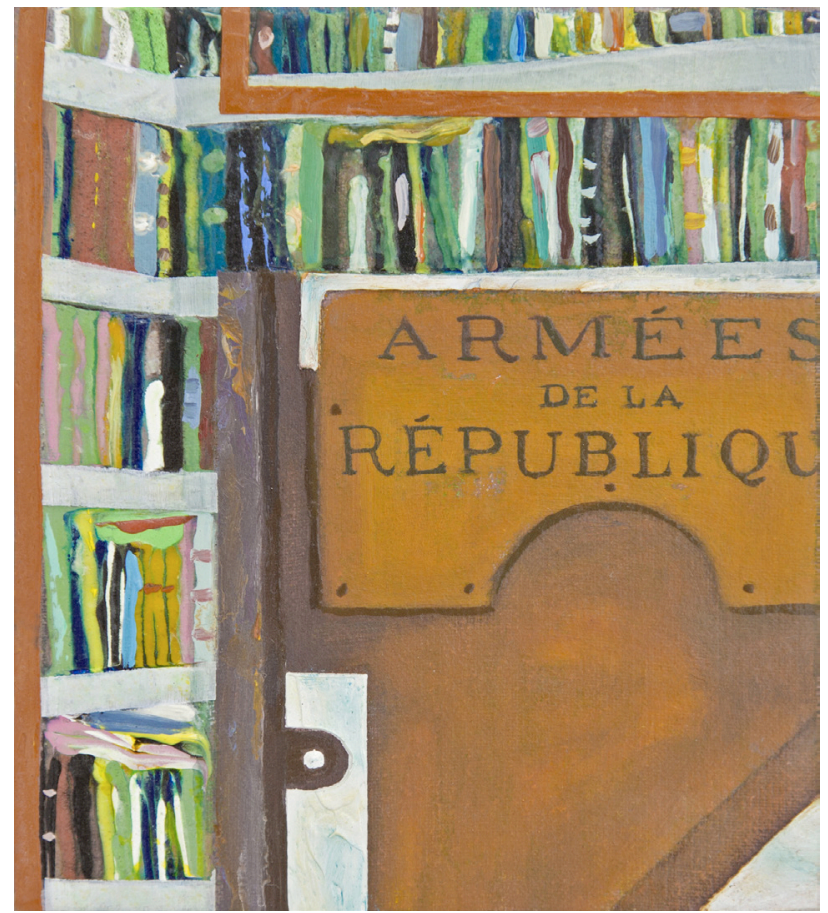

3. Carlos Miranda, The Estate of Anonymous (VII): Stories from homes 3. Galería JM. Málaga, 2014. Acrílico y óleo sobre tela. 12 × 11 cm. 2014

sentido, la voluntad y el acto representacional tienen para el artista un doble significado: uno «extensional», compartido por todas las obras, que se circunscribe a un espacio de trabajo y de eclosión determinado; y otro «intensional», que revela un significado y dimensiones más profundas y particulares en cada caso. La pretensión representacional es un modelo de expresión que pretende «captar el contenido de estados, actitudes o actuaciones intensionales», como nos indica Robert Brandom en su ensayo Hacerlo explícito. Y en esa captación, en el relato de la cotidianidad, persona y artista, hogar y taller, hábito y excepción, conciliación y conflicto, se funden y mixturan sin solución de continuidad. Como en la vida. Como en el arte.

Iván de la Torre Amerighi Universidad de Málaga 